\title{
Ligaplants: A New Era in Dental Engineering
}

\author{
Lipika Gopal ${ }^{1 *}$, Anchal Varshney ${ }^{2}$, Ashim Aggarwal ${ }^{3}$ and Shivani Aggarwal ${ }^{4}$ \\ ${ }^{1}$ Research Scholar, Reader, Faculty of Dental Sciences, MRIIRS, Faridabad, India \\ ${ }^{2}$ Research Scholar, Sr. Lecturer, Faculty of Dental Sciences, MRIIRS, Faridabad, India \\ ${ }^{3}$ Department of Oral and Maxillofacial Surgery, Faculty of Dental Sciences, MRIIRS, Faridabad, India \\ ${ }^{4}$ Department of Oral Pathology and Microbiology, Faculty of Dental Sciences, MRIIRS, Faridabad, India
}

\section{ABSTRACT}

In today's era, replacement of teeth by a more advanced and fixed therapeutic modality has gained popularity in the field of dentistry. Natural tooth consists of periodontal ligament which acts as a shock absorber providing tooth movement in the socket and also delivers the progenitor cells for alveolar bone formation and remodelling. Dental implants serve as the prosthesis with lacking this ligament tissue further laying out a direct attachment of the implant with the bone. This reduces the biological performance. Currently osseointegrated implants are agreed to be highly acceptable implants based on high clinical long term survival rate. Tissue engineering has laid the foundation of implants with periodontal ligament which has provided a breakthrough in the surgical field of dentistry. This quantum leap is termed as Ligaplants serving as a perfect replica of tooth in the socket. It can be described to be a combination of implants with ligament. They are considered to be an innovative treatment modality for teeth replacement, several trials being done in invivo and invitro. Ligaplants are being studied to prolong the life of prosthesis duplicating the natural tooth. This review paper provides an insight of the various procedures for obtaining Ligaplants, the risk factors involved and the merits and demerits of this development. Also, the clinical importance will be given an emphasis during the placement of ligaplants.

KEY WORDS: LIGAPLANTS, TISSUE ENGINEERING, DENTAL IMPLANTS, PERIODONTAL LIGAMENT.

\section{INTRODUCTION}

\section{Ligaplants: A New Era in Dental Engineering: Implant dentistry has become a called for branch of conventional dental field in this generation of dental practice. Fixed and partial dentures are restored by implants which further improves the quality of life. The reverberation of this speciality is a combination of various reasons such as failures linked to fixed partial denture and removable partial dentures and also prolonging the life span of ageing population.}

The high predictability and long term success rate can be attributed to the attachment of implant with bone post cellular and molecular activities taking place at the implant bone interface. Branemark's work contributed to the osseointegrated dental implants which shows the

Biosc Biotech Res Comm P-ISSN: 0974-6455 E-ISSN: 2321-4007

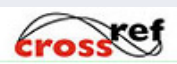

Identifiers and Pagination

Year: 2021 Vol: 14 No (5) Special Issue

Pages: $349-351$

This is an open access article under Creative

Commons License Attribn 4.0 Intl (CC-BY).

DOI: $h t t p: / / d x$.doi.org/10.21786/bbrc/14.5/59 direct contact between bone and implant. This direct attachment is termed as "Osseointegration". There have been various complications pertaining to implants which can be operator and patient factors or surgical procedure related. The success rate of implants depends on factors such as sufficient jaw bone height and width, operator's experience, patient case selection and the type of dental implant chosen.

Periodontal ligament is a highly vascular connective tissue which acts like a shock absorber allowing tooth movement in its socket. Various vital cells such as osteoblasts, cementoblasts, osteoclasts, cementoclasts and fibroblasts resides in this ligament. The undifferentiated mesenchymal cells which also are accomodated in this tissue shows the amount of regeneration and reestablish the strength of biomechanical tissue. With the extraction of natural teeth, the bony socket is just an empty socket without periodontal ligament attachment fibres. These fibres are lost with the tooth. Due to the absence of these fibres and the periodontal ligament cells there is no regeneration of the ligament possible. Therefore, when implant is placed, the process of healing results in direct bone implant attachment without any intervening ligament for attachment. Due to lack of this periodontal

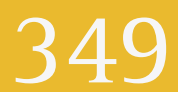


ligament in implants, there is ankylosis and no mobility as in natural tooth. Many treatment modalities have been planned to improve this property which include alteration of implant surface by surface treatment and growth factors introduced into implant surface.

There was a study conducted by Buser et al1, in which they concluded that when Titanium implants come in proximity to retained root tips, the periodontal ligament houses the cells which envelopes the implant surface during healing. However, a new prospect called “ Tissue Engineering" have paved the way in the field of periodontal regeneration. Tissue engineering is known to be a new promising therapeutic approach utilising the dental stem cells for regeneration of new tissues. Tissue engineering involves the three key elements namely scaffold, signaling molecules and cells. The difficulties arousing in the present dental implants can be resolved by development of periodontal ligament cells around by the bioengineering involving the periodontal ligament cell regeneration around the implants. The fusion of the periodontal ligament cells with implants have been termed as "Ligaplants" which is yet again a boon in implant dentistry.

Footing of Ligaplants: The interdisciplinary field of tissue engineering shows the principle of engineering and life sciences for evolution of biological substitutes which upgrades and preserves tissue function. This was pioneered by "Langer And Vacanti"2. The study conducted by Lin et al derieved the autologous rat periodontal ligament cells from molar root surface3. A 3 dimensional matrix scaffold called"matrigel" was introduced to organise rat periodontal ligament regeneration at the Titanium implant bone interface. Also, it was observed that periodontal ligament fibroblasts could be harvested from teeth with hopeless prognosis and the cells when further cultured in bioreactors, preserves the differentiation state4. The study carried out showed the extraction of donor tooth, 14days before transplantation and then the same tooth was instantly reimplanted in the actual alveolus. The process of cell proliferation and differentiation occurs during the healing of periodontal ligament which starts as soon as this intentional injury occurs. Post 14 days, the invivo cellular activity enhances and is at its highest activity rate. At this period, the process of transplantation of tooth is done as there are many cells with peak activity attached to its root by the new Sharpey's fibres5,6. Based on this clinical and biological representation, a similar cell culture is conducted around artifical root using engineering process.

The laboratory steps involved for the invention of this new device is as follows:

Culture Dishes Preparation: The Polystyrene culture dishes were taken and were treated with $\mathrm{N}$ isopropylacylamide monomer along with 2-propanaol solution. These dishes were irradiated with electron beam. Thorough rinsing of the polymer grafted dishes with cold water is done to remove engrafted monomer. These dishes were then sterilized with ethylene oxide 7,8.
Culturing of the cell: The periodontal ligament cells are obtained from the extracted tooth. The periodontal tissue is scraped with the help of scalpel blade from the middle third portion of the root. Dulbecco's modified eagle's minimal essential medium, supplemented with $10 \%$ fetal bovine serum and 100 units/ml of penicillinstreptomycin is used as the culture medium. The cells obtained from the extracted tooth are now placed on the culture dishes which are kept in a humidified atmosphere of $5 \% \mathrm{CO}_{2}$ at $37{ }^{\circ} \mathrm{C}$. this is supplemented with $50 \mathrm{mr} / \mathrm{ml}$ ascorbic acid 2-phosphate, 10nm dexamethasone and $10 n M \beta$-glycerophosphate. These all substances together will provide an osteodifferentiation medium9.

Bioreactor: Hydroxyapatite coated titanium pins are placed inside a hollow plastic cylinder. These pins are placed in such a manner that at a gap of $3 \mathrm{~mm}$ is left around the pin. Culture medium is continuously pumped through the gap. These titanium pins are kept under the growth medium for a time period of 18 days 10,11 .

\section{Merits}

a. Replica of natural tooth root in the alveolar bone socket.

b. The gingival recession and alveolar bone defects of missing tooth can be decreased.Therefore, second surgical option such as bone grafting not required by the patient. The ligaplant induces new bone formation even at large periodontal defect sites eliminating the surgical requirement of bone grafting 11 .

c. The periodontal ligament offsets lateral and vertical tooth wear throughout the individual's life span. Thus, there is an adequate movement of the implant inside the bony socket.

\section{Demerits}

a. The culturing process is highly technique sensitive b. The factors taken into consideration is the culture cells, temperature and duration of culture. It can also cause failure in development of periodontal ligament cells. c. Acceptance by the host is highly unpredictable. d. Cost of Ligaplant is because of deficient facilities.

\section{DISCUSSION}

In a study done by Gomez Flares M et al in 200812, a multi-layered periodontal ligament cell sheet was found to have regenerative capacity of periodontal ligament and therefore concluded that this strategy can be used for periodontal ligament cell regeneration. Nunez et al in 201213, showed the regenerative potential of periodontal ligament derieved mesenchymal cells. Invivo experiments demonstrated the migration of cementoblast and periodontal ligament fibroblast precursor cells towards dental implant when the implant was in closer proximity to these cells. In a review done by Gulati et al in 201214, many research from Pubmed, Elseiver and Blackwell were extracted and showed succesful studies on Ligaplants and concluded that these implants are a boon to implant dentistry. Kiong and Arjunkumar stated that the surgery of ligaplants are considered to be comparatively easy as the implant is not fitted tightly 
to its site due to the periodontal ligament regeneration in between the implant and bone9.

Parlar et al demonstrated that all the tissues of periodontium occupied the implant and bone interface in dog models for periodontal regeneration15. Results of the study done by Byung-Ho Choi in 2000 revealed that once Titanium screw-type implant was placed and the periodontal ligament cells from mid root surface was utilised, there was a perio-integration at the implant and bone interface16. The regenerative potential of periodontal ligament depends on an array of signaling molecules. These molecules consist of their own anatomic code and homeogene-coded transcription factors.The synthesis of cell surface is forced by the homeoproteins. The signals from the cellular surface send a feedback to alter homeogene expression, whereby cell identities are formed based on tissue type and anatomical site. If the mineral formation has to be inhibited, an SLRP protein called asporin is established. However, this has lead to a thought over the risk of Ligaplants and its success rate17.

\section{CONCLUSION}

Majority of the literature is done in animals and have showed the generation potential of periodontal ligament like tissue arounfd the implants. Further studies are required in humans as well to understand the function, survival rate and sucesess of Ligaplants. Therefore, validity of these implants are essential in each research. This revolutionary approach of developing periodontiointegrated implants; has opened up the current implant scenario which have taken implant dentistry to yet another level.

\section{REFERENCES}

Aeran H, Tuli AS, Anamika. Ligaplants: Recreation of a natural link in implant dentistry: A review. Int J Oral Health Dent 2021;7(1):3-7.

Bathla N, Sailo JL, Kapoor N, Nagpal A, Gupta R, Singla A. Ligaplants, the next-generation prosthodontic implants: A comprehensive review. Indian J Dent Sci 2021;13:146-9.

Buser D, Warrer K, Karring T. Formation of a periodontal ligament around titanium implants. J Periodontol 1990;61:597 601 .

Deepa D, Garg H. Bioengineered periodontal ligament: Ligaplants, a new dimension in the field of implant dentistry - Mini review. J Oral Res Rev. 2018;10(2):92-5.
Gault P, Black A, Romette JL, Fuente F, Schroeder K, Thillou F, et al. Tissue-Engineered ligament: Implant constructs for tooth replacement. J Clin Periodontol 2010;37:750-8.

Giuseppe Polimeni, Andreas V. Xiropaidis \& ULF M. E. Wikesjo. Biology and principles of periodontal wound healing/ regeneration. Journal of Periodontology 2000. $41,30-47$

Gomez et al , Cementum-periodontal ligament complex regeneration using the cell sheet technique J Periodont Res 2008; 43: 364- 371.

Gulati M, Anand V, Govila V, Jain N, Rastogi P. Bahuguna $r$ et al. Periodontio-integrated implants: A revolutionary concept. Dent Res J 2014;11(2):154-62.

Kiong Al, Arunkumar R. Tissue-engineered ligament: Implant constructs for tooth replacement (ligaplants). J Pharm Sci Res 2014;6:158-60.

Langer R, Vacanti JP. Tissue engineering. Science 1993;260:920-6.

Lin Y, Gallucci GO, Buser D, Bosshardt D, Belser UC, Yelick PC. Bioengineered periodontal tissue formed on titanium dental implants. J Dent Res 2011;90:251-6.

Mathew A, Babu AS, Keepanasseril A. Biomimetric properties of engineered periodontal ligament/ cementum in dental implants. Contemp Clin Dent. 2020;11(4):301-10.

Moussa RM, Yassin HH, Saad MM, Nagy NB. Marei MK. Periodontal tissue engineering around dental implants. Stem cell biology and tsuue engineering in dental sciences 2015. Elseiver publications. 765-74.

Phileppe C. Gault \& Waroquier-Clerout, R.Tooth autotransplantation with double periodontal ligament stimulation to replace periodontslly compromised teeth. Journal of Periodontology 2002. 73, 575-583

Pinkerton MN, Wecott DC, Gaffey BJ, Beggs KT, Milne TJ, Meikle MC. Cultured human periodontal ligament cells constituitively express multiple osteotropic cytokines and growth factors, several of which are responsive to mechanical deformation. J Periodontol Res 2008;43:343-51..

Singh R, Raj S, Singh GB, Nikunj AM, Chaurasia S. Ligaplants:Periodntio-Integrated Implants. IOSR J Dent Med Sci. 2019;18(7):61-64.

Yamada S, Tomoeda M, Ozawa Y, Yoneda S, Terashima Y, Ikezawa S, et al. PLAP-1/asporin, a novel negative regulator of periodontal ligament mineralization. Journal of Biological Chemistry 2007;282:230703080 . 